\title{
ОЦЕНКА ИНТЕНСИВНОСТИ ПРОСАЧИВАНИЯ ГАЗА ИЗ ВЫРАБОТАННОГО ПРОСТРАНСТВА ЧЕРЕЗ ТРЕЩИНУ В МЕЖСТОЛБОВОМ ЦЕЛИКЕ И СОЛЕБЕТОННОЙ ПЕРЕМЫЧКЕ
}

\author{
Е.В. Колесов \\ Горный институт УрО РАН, г. Пермь
}

\begin{abstract}
Аннотация. В статье приведена оценка скорости и расхода воздуха из выработанного пространства через узкую поперечную щель в межстолбовом целике и солебетонной перемычке в предположении ламинарного характера движения газовоздушной среды. Получены зависимости средней скорости воздуха через щель от приложенного перепада давления при разных мощностях целика и толщинах перемычки.

Ключевые слова: выработанное пространство, газопроницаемость, бесцеликовая выемка, солебетонная перемычка.
\end{abstract}

\section{Введение}

Подземная добыча калийной руды на рудниках ОАО «Беларуськалий» осуществляется длинными очистными забоями или лавами с применением шнековых комбайнов в составе очистных механизированных комплексов. При этом актуальной задачей является сокращение потерь полезного ископаемого в охранных межстолбовых целиках, в связи с чем одним из направлений совершенствования технологии отработки калийных пластов является сокращение размеров межстолбовых целиков или их полная выемка. Для реализации этой идеи разработаны технологические схемы бесцеликовой выемки полезного ископаемого.

Пример технологической схемы бесцеликовой выемки представлен на рис. 1 [1].



Рис. 1. Схема выработок столба лавы. 1 - транспортный штрек; 2 - конвейерный штрек;

3 - вспомогательный штрек; 4 - закладочный штрек; 5 - вентиляционный штрек; 6 - транспортный штрек соседнего отработанного столба; 7 - лава;

8 - направление отработки столба; 9 - технологическая сбойка

При использовании данной схемы очистная выработка (лава) одним концом примыкает к выработанному пространству соседнего отработанного столба. Для проветривания концевой части лавы и сброса части отработанной воздушной струи используется транспортный штрек соседнего отработанного столба. 
Однако опыт применения бесцеликовых схем разработки показал, что при ведении очистных работ возникали негативные явления вследствие разрушения краевой части массива столба. Обнаружено образование продольных трещин (рис. 2) с последующим обрушением стенок и кровли транспортного штрека соседнего столба. Оценить его состояние (протяженность его разрушающейся части, характер распределения трещин) крайне затруднительно в связи с опасностью нахождения в штреке.
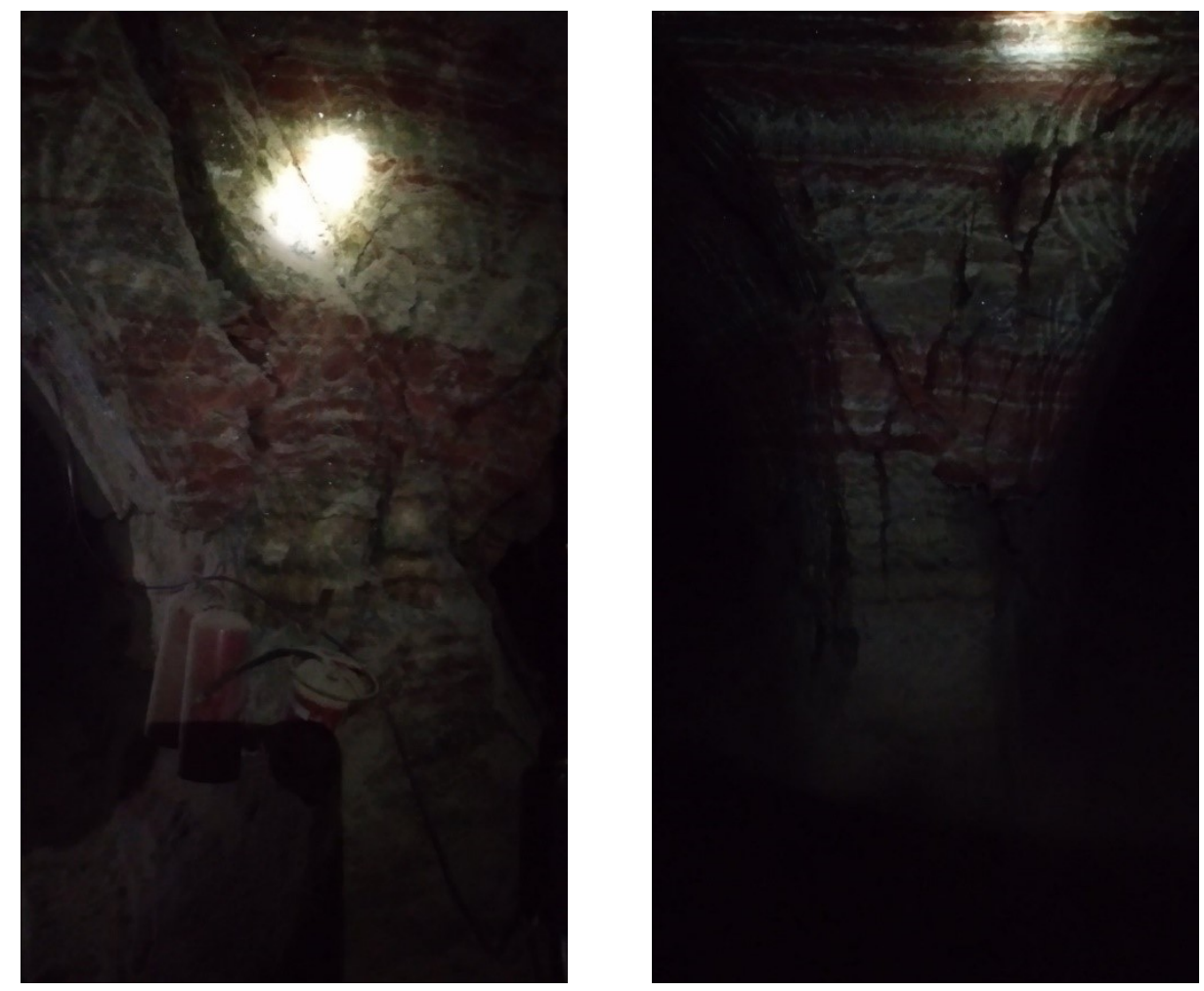

Рис. 2. Продольные трещины в целиках (вид с торцов)

Согласно [1], процессы трещинообразования и разрушения горных выработок в краевой части лавы обусловлены возникновением и развитием в процессе ведения очистных работ в угловой части столба лавы зоны повышенной концентрации напряжений в горном массиве вынимаемого пласта вследствие интегральной нагрузки от подработанного массива позади очистного забоя и со стороны смежного отработанного ранее столба. Отягчающим фактором при этом является увеличение скорости продвижения лавы вследствие интенсификации очистных работ, что приводит к дополнительным динамическим эффектам, связанным с перераспределением опорного горного давления.

В работах [2-12] применялось CFD-моделирование для исследования динамики ядовитых и взрывоопасных газов в выработанном пространстве длинных очистных забоев, а также в горных выработках рабочих зон. Как правило, в существующих работах построение моделей осуществлялось на основании расчета проницаемости и пористости выработанного пространства $[3,4,6]$. В работах $[4-6,8]$ прохождение газа через выработанное пространство моделировалось как ламинарное течение сквозь пористую среду, а данные по проницаемости выработанного пространства лавы получены на основании геотехнического моделирования.

Ряд работ посвящен анализу способов предотвращения выбросов породы и газа в условиях применения различных вариантов столбовой системы разработки [13-17], а также способам определения газообильности рудничной атмосферы [18]. 
Следует отметить, что в существующих работах отсутствуют исследования, дающие геомеханическую оценку условий появления поперечных трещин в межстолбовых целиках и солебетонных перемычках, а также оценку интенсивности просачивания газов из выработанного пространства через поперечные трещины. В настоящей работе приведены результаты аналитических расчетов по определению газопроницаемости межстолбовых целиков и солебетонных перемычек в случае образования в них поперечных трещин.

\section{Математическая модель движения газа через поперечную щель в целике}

Для оценки скорости и расхода воздуха через узкую поперечную щель в целике принята гипотеза о ламинарном характере его движения. Данная гипотеза дает оценку сверху на скорость (и расход) газа по сравнению с рассмотрением данного процесса в предположении турбулентного режима течения воздуха.

Характер потока газа, турбулентный или ламинарный, определяется безразмерным числом Рейнольдса $R e$, которое в случае движения газа через узкую щель определяется следующим соотношением:

$$
R e=\frac{V \cdot h}{v}
$$

где $V$ - характерная скорость потока, м/с; $h$ - ширина щели, м; $v$ - кинематическая вязкость газа, $\mathrm{m}^{2} / \mathrm{c}$. При значениях числа Рейнольдса менее некоторого критического для данной геометрии $\left(R e<R e_{c}\right)$ течение происходит в ламинарном режиме. При значениях чисел Рейнольдса, близких к критическому, движение теряет устойчивость и происходит переход к турбулентному режиму. При $R e \gg R e_{c}$ движение происходит в режиме развитой турбулентности. Критическое значение числа Рейнольдса отличается для разных типов течений, и для течения газа через узкую щель его значение порядка $10^{3}$. Принимая ширину щели порядка $10^{-2} \mathrm{M}$, а значение кинематической вязкости газа $1,5 \cdot 10^{-6} \mathrm{~m}^{2} / \mathrm{c}$, получим оценку критической скорости газа $1,5 \mathrm{~m} / \mathrm{c}$.

Рассмотрим движение воздуха между двумя вертикальными параллельными плоскостями $y=0$ и $y=h$ (рис. 3).

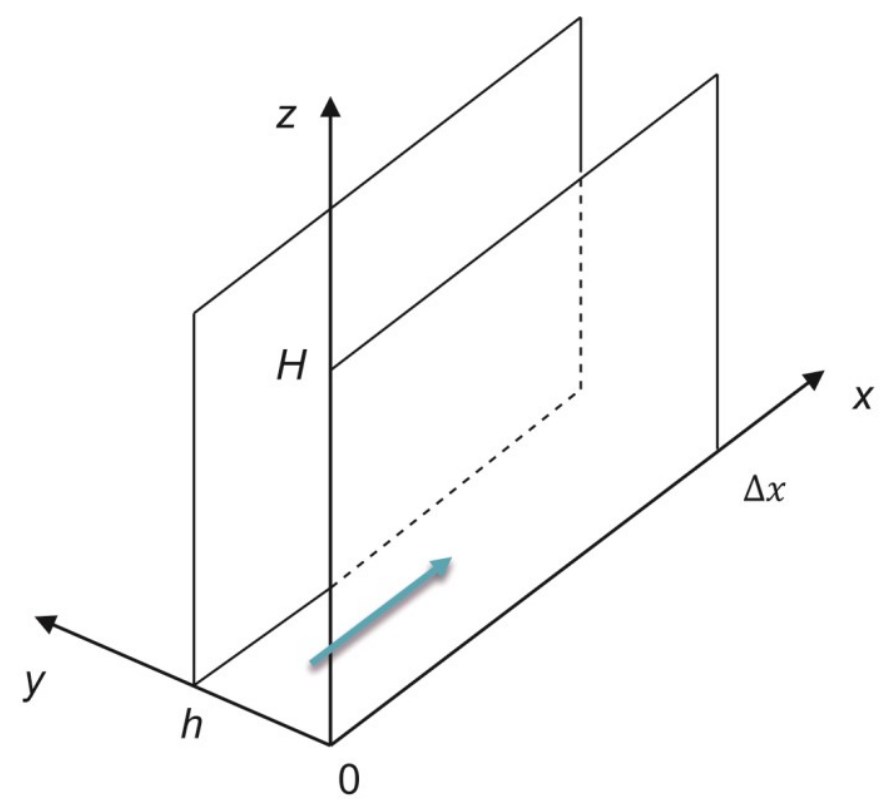

Рис. 3. Принципиальная схема движения воздуха через щель ширины $h$ в целике высотой $H$ и мощностью $\Delta x$ 
Поскольку в рассматриваемом случае движение можно считать стационарным и плоским, а скорость не зависит от координаты $z$, т.е. $\vec{v}=(v(y), 0,0)$ то уравнения Навье-Стокса для описания течения воздуха в приближении вязкой несжимаемой жидкости:

$$
\rho\left(\frac{\partial \vec{v}}{\partial t}+\vec{v} \cdot \nabla \vec{v}\right)=-\nabla p+\mu \Delta \vec{v}
$$

в проекции на оси $x$ и $y$ упрощаются до:

$$
\begin{gathered}
\frac{d^{2} v}{d y^{2}}=\frac{1}{\mu} \frac{d p}{d x} \\
\frac{d p}{d y}=0
\end{gathered}
$$

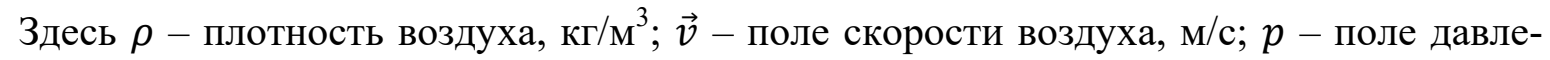
ния, Па; $\mu$ - динамическая вязкость воздуха, Па·с.

В левой части (2) стоит функция только от $y$, а справа - только от $x$. Такое уравнение может выполняться, только если его левая и правая части являются константами. Из граничных условий прилипания, т.е. $\vec{v}=0$ при $y=0$ и $y=h$, получим решение для скорости:

$$
v=\frac{1}{2 \mu} \frac{\Delta p}{\Delta x} y(y-h) .
$$

Для среднего по толщине слоя скорости воздуха получим значение:

$$
\bar{v}=\frac{1}{h} \int_{0}^{h} v d y=\frac{h^{2}}{12 \mu} \frac{\Delta p}{\Delta x} .
$$

Для расхода воздуха через щель шириной $h$ и высотой $H$ получим выражение:

$$
Q=\int v d S=\int_{0}^{H} d z \int_{0}^{h} v d y=\frac{H h^{3}}{12 \mu} \frac{\Delta p}{\Delta x} .
$$

Для визуализации зависимости средней скорости и расхода воздуха, проходящего через щель, в зависимости перепада давления для разных мощностей целика $\Delta x$, построена серия графиков (рис. 3 и рис. 4). В качестве исходных данных для построения зависимостей приняты следующие значения параметров: $H=3 \mathrm{~m}$; $h=0,01 \mathrm{M}$;

$$
\mu=1,8 \cdot 10^{-5} \text { Па } \cdot \text { c. }
$$

Расчеты показали, что максимальная скорость воздуха в трещине целика шириной 1 см при депрессии 50 Па составляет 7,2 м/с, при этом расход воздуха через образовавшуюся трещину составляет $0,23 \mathrm{~m}^{3} / \mathrm{c}$. 


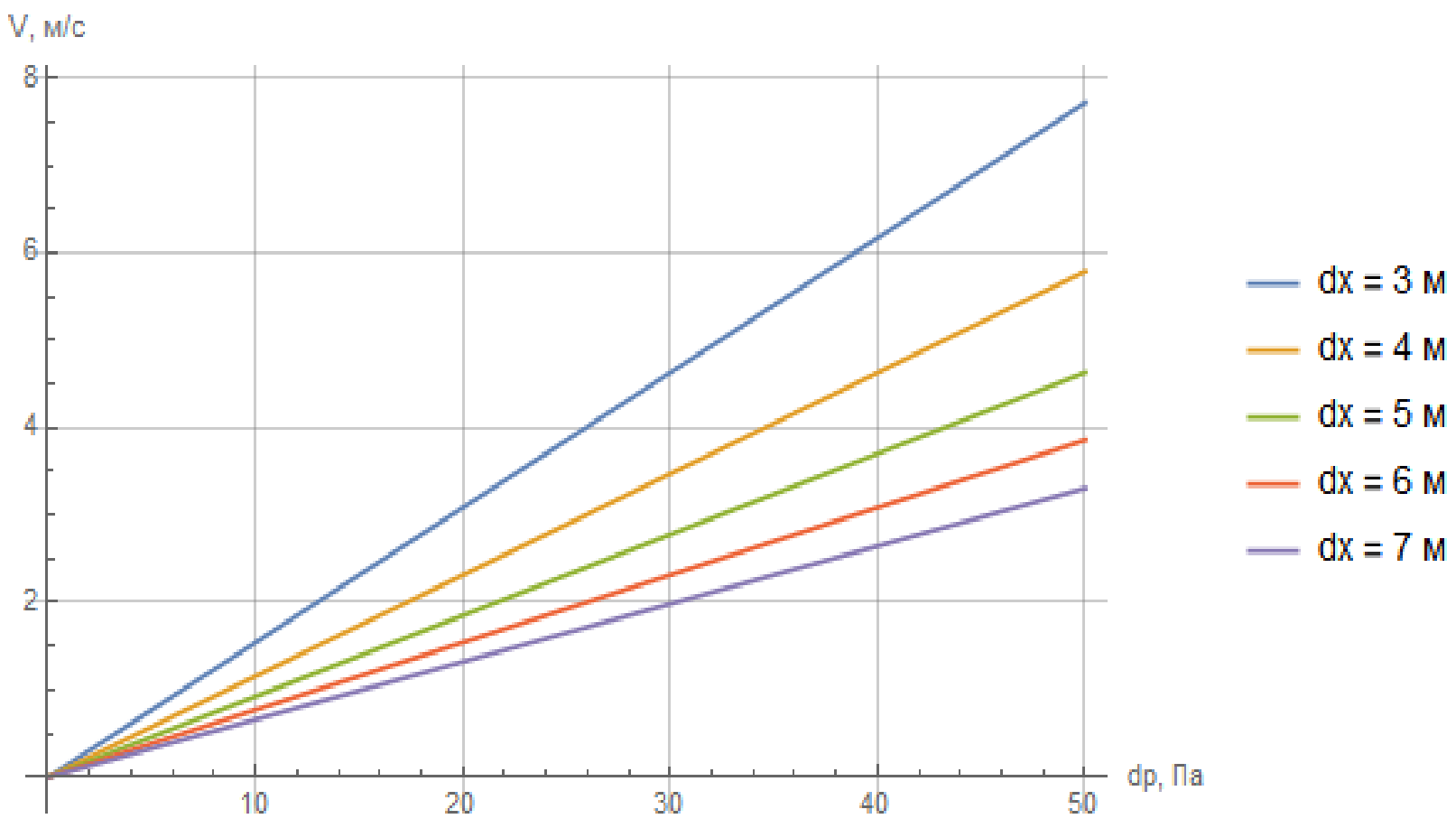

Рис. 4. Зависимость средней скорости воздуха через щель от приложенного перепада давления при разных мощностях целика

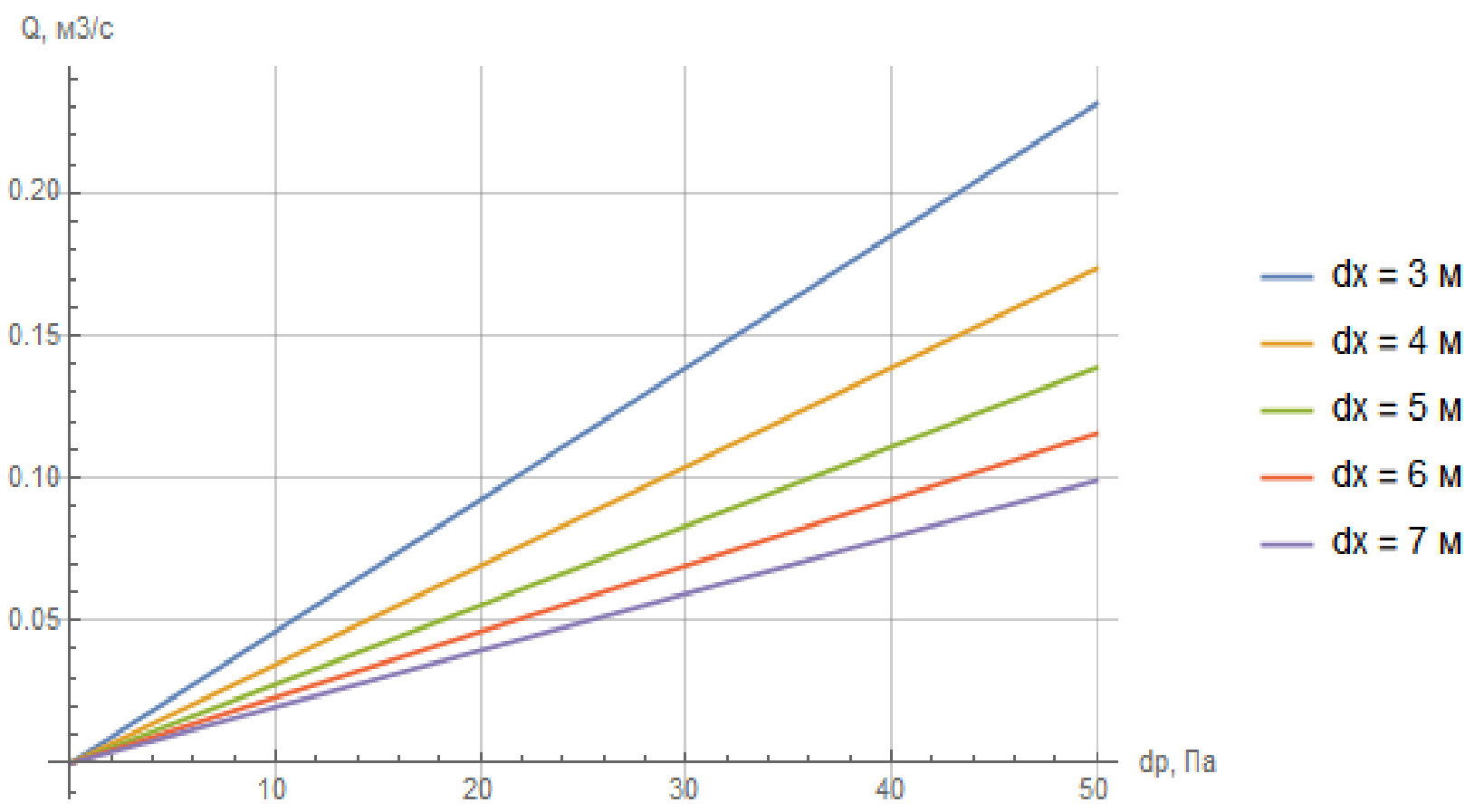

Рис. 5. Зависимость расхода воздуха через щель от приложенного перепада давления при разных мощностях целика

\section{Определение газопроницаемости трещиноватых перемычек}

Далее выполнены расчеты воздухопроницаемости вентиляционных сооружений (солебетонных перемычек) при возникновении в них продольных или поперечных трещин шириной $0,01 \mathrm{M}$. 


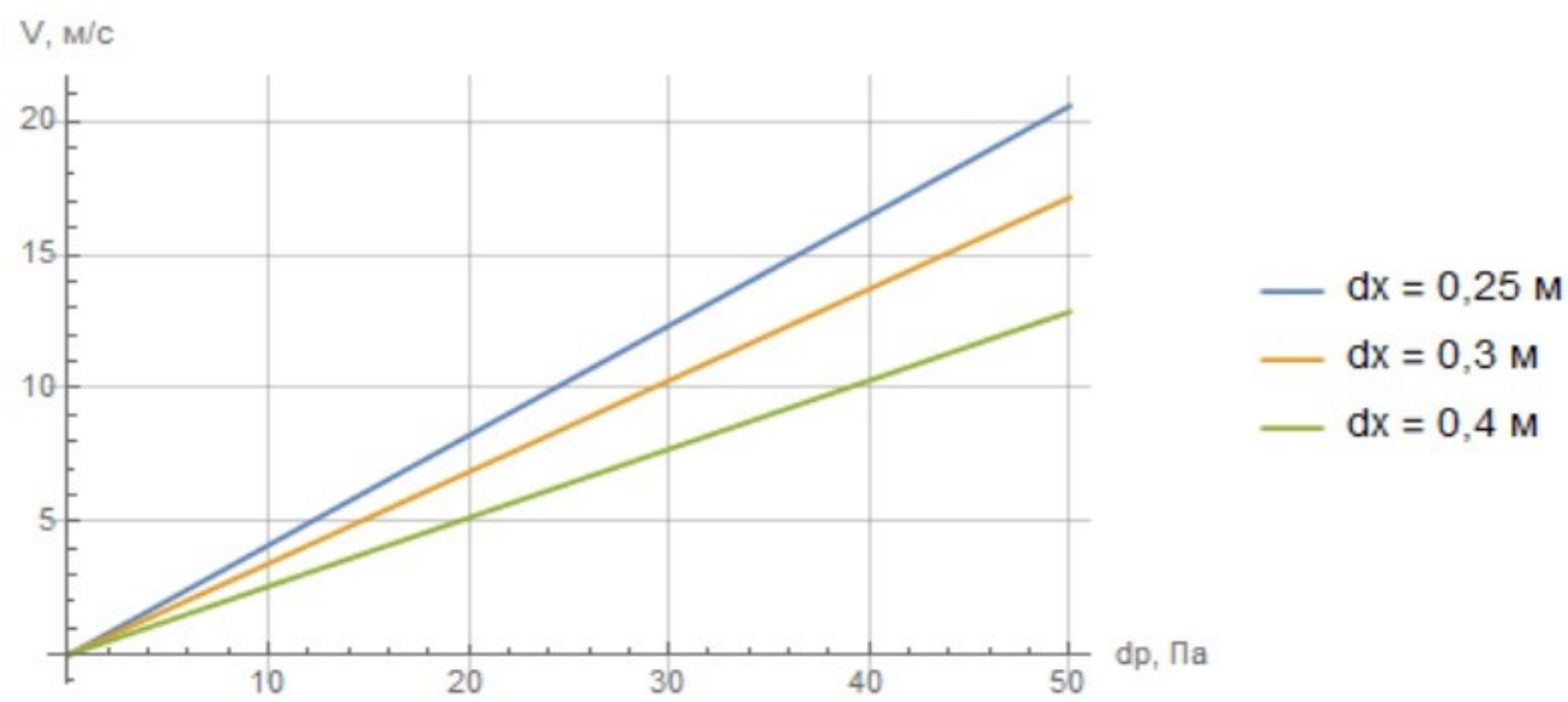

Рис. 6. Зависимость скорости воздуха через перемычку от приложенного перепада давления при различных толщинах перемычки

Q, M3/c

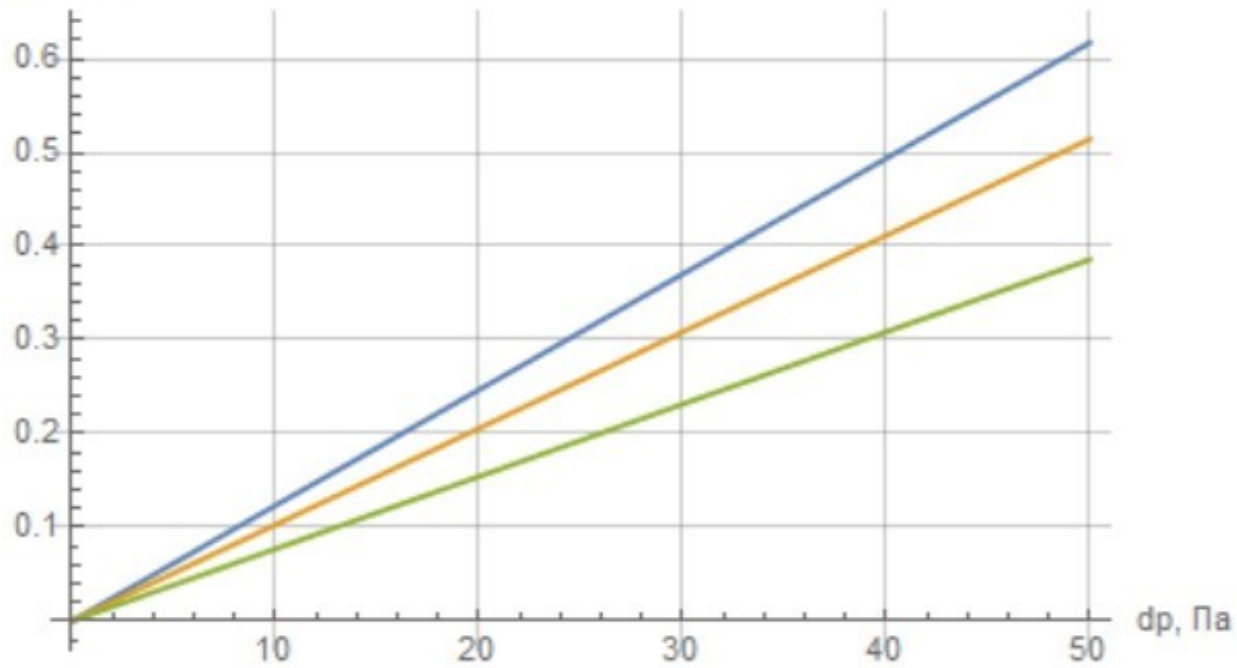

$-\mathrm{dx}=0,25 \mathrm{M}$

$-\mathrm{dx}=0,3 \mathrm{M}$

$-\mathrm{dx}=0,4 \mathrm{M}$

Рис. 7. Зависимость расхода воздуха через перемычку от приложенного перепада давления при различных толщинах перемычки

Расчеты показали, что максимальная скорость воздуха в трещине перемычки шириной 1 см при депрессии 50 Па составляет $21 \mathrm{~m} / \mathrm{c}$, при этом расход воздуха через образовавшуюся трещину $0,63 \mathrm{~m}^{3} / \mathrm{c}$.

Следует отметить, что результаты получены в предположении ламинарного режима движения воздуха и без учета геометрии и шероховатости стенок трещин. Таким образом, полученные значения скоростей и расходов являются оценкой сверху для газопроницаемости межстолбовых целиков и солебетонных перемычек; в шахтных условиях данные параметры будут иметь меньшие значения. Результаты работы могут быть использованы в качестве начального приближения в газодинамических расчетах в моделях вентиляционных сетей рудников, в которых применяются технологические схемы бесцеликовой выемки полезного ископаемого.

Исследование выполнено при финансовой поддержке Министерства науки и образования РФ в рамках соглашения по государственному заданию № 075-03-2021-374 от «29» декабря 2020 г. 


\section{БИБЛИОГРАФИЧЕСКИЙ СПИСОК}

1. Алыменко Н.И., Петров А.И. Технология отработки пластовых месторождений столбовыми системами разработки с косыми длинными очистными забоями в условиях Старобинского месторождения калийных солей / Н.И. Алыменко, А.И. Петров // Вестн. Перм. ун-та. Сер. Геология. - 2012. - Вып. 1 (14). - C. 69-84.

2. Kaledina N.O., Kobylkin S.S., Kobylkin A.S. The calculation method to ensure safe parameters of ventilation conditions of goaf in coal mines // Eurasian Mining. - 2016. - № 1. - P. 41-44.

3. Esterhuizen G., Karacan C. A methodology for determining gob permeability distributions and its application to reservoir modeling of coal mine longwalls // SME Annual Meeting and Exhibit. - Denver, 2007. -

4. Yuan L., Smith A.C., Brune J.F. Computational fluid dynamics study on ventilation flow paths in longwall gobs // Proceedings of the $11^{\text {th }}$ U.S./ North American Mine Ventilation Symposium North American Mine Ventilation Symposium. - Pennsylvania, 2006 - P. 591-598.

5. Tanguturi K., Balusu R. CFD modeling of methane gas distribution and control strategies in a gassy coal mine // Journal of Computational Multiphase Flows. - 2014. V. 6, № 1. - P. 65-78. - DOI: 10.1260/1757482X.6.1.65.

6. Lolon S.A., Brune J.F., Bogin G.E., Grubb J.W., Saki S.A., Juganda A. Computational fluid dynamics simulation on the longwall gob breathing // International Journal of Mining Science and Technology. - 2017. V. 27, № 2. - P. 185-189.

7. Ren T., Wang Z., Liang Y., Zhang J. Numerical investigation of $\mathrm{CO}_{2}$ fringe behaviour on a longwall face and its control // International Journal of Coal Geology. - 2018. - V. 186. - P. 80-96.

8. Saki S.A., Brune J.F., Bogin G.E., Grubb J.W., Emad M.Z., Gilmore R.C. CFD study of the effect of face ventilation on $\mathrm{CH} 4$ in returns and explosive gas zones in progressively sealed longwall gobs // Journal of the Southern African Institute of Mining and Metallurgy. - 2017. - V. 117, № 3. - P. 257-262. - DOI: 10.17159/2411-9717/2017/v117n3a7.

9. Brodny J., Tutak M. Forecasting the distribution of methane concentration levels in mine headings by means of model-based tests and in-situ measurements // Archives of Control Sciences. - 2019. - V. 29. - № 1. - P. 25-39. - DOI: 10.24425/acs.2019.127521.

10. Mishra D.P., Kumar P., Panigrahi D.C. Dispersion of methane in tailgate of a retreating longwall mine: a computational fluid dynamics study // Environmental Earth Sciences. - 2016. - V. 75, № 6, - Номер статьи 475. - DOI: 10.1007/s12665-016-5319-9.

11. Kumar P., Mishra D.P., Panigrahi D.C., Sahu P. Numerical studies of ventilation effect on methane layering behaviour in underground coal mines // Current science. - 2017. - V. 112, № 9. - P. 1873-1881. - DOI: 10.18520/cs/v112/i09/1873-1881.

12. Wala A.M., Vytla S., Huang G., Taylor C.D. Study on the effects of scrubber operation on the face ventilation // Proceedings of the $12^{\text {th }}$ U.S./ North American Mine Ventilation Symposium, june 9-12 2008. - Reno, Nevada, 2008 - P. 281-286.

13. Андрейко С.С. Предотвращение выбросов породы и газа при проходке подготовительных выработок в доломитовых породах на больших глубинах // Горное эхо. - 2020. - № 2 (79). - С. 83-91. - DOI: 10.7242/echo.2020.2.17.

14. Володин А.С., Андрейко С.С. Анализ способов предотвращения выбросов породы и газа при ведении подготовительных горных работ во вмещающих породах на больших глубинах // Актуальные проблемы повышения эффективности и безопасности эксплуатации горношахтного и нефтепромыслового оборудования. - 2019. - Т. 1. - С. 133-138.

15. Андрейко С.С., Иванов О.В., Нестеров Е.А. Исследование способов предотвращения внезапных отжимов призабойной части соляных пород // Горный журнал. - 2018. - № 6. - С. 30-34. - DOI 10.17580/gzh.2018.06.06.

16. Андрейко С.С. Предотвращение газодинамических явлений из почвы горных выработок в условиях применения различных вариантов столбовой системы разработки Третьего калийного пласта на рудниках ОАО «Беларуськалий» // Стратегия и процессы освоения георесурсов: сб. науч. тр. Вып. 15 / ГИ УрО РАН. - Пермь, 2017. - С. 341-345.

17. Андрейко С.С., Литвиновская Н.А., Сиренко Ю.Г., Чаянов А.Б. Предотвращение газодинамических явлений из почвы горных выработок при различных вариантах столбовой системы разработки на рудниках ОАО «Беларуськалий» // Горн. журн. - 2018. - № 8. - С. 29-33. - DOI 10.17580/gzh.2018.08.02.

18. Исаевич А.Г., Стариков А.Н., Мальцев С.В. Совершенствование метода отбора проб воздуха для определения относительной газообильности горючих газов в рудничной атмосфере // Горный информационно-аналитический бюллетень (научно-технический журнал). - 2021. - № 4. - С. 143-153. - DOI: 10.25018/0236-1493-2021-4-0-143. 